\begin{tabular}{cc}
\hline & International Journal of Engineering \& Technology, $7(4.36)(2018) 580-585$ \\
SPC & International Journal of Engineering \& Technology \\
Website: www.sciencepubco.com/index.php/IJET & Research paper \\
\hline
\end{tabular}

\title{
Formation of New Ligands Imine- (Oxazole, Thiazole, Thiophene) And Study of (Chemical Investigation and Chromatographic Applications)
}

\author{
MostafaN. Mohamed Salih ${ }^{1}$, Zaid Noor ObaidAl-Husseini², NaghamMahmood Aljamali ${ }^{3 *}$ \\ ${ }^{I}$ Ministry of Education, Hutheifa Bin Al-YemanIntermediate School, Iraq. \\ ${ }^{2}$ Ministry of Education, Babylon Directorate of Education, Yahya Bin ZaidPreparatory School, Iraq. \\ ${ }^{3}$ Department of Chemistry, Factuality of Education, Kufa University, Iraq. \\ *Corresponding author E-mail: Dr.Nagham_mj@yahoo.com
}

\begin{abstract}
(Oxazole, Thiazole, Thiophene) derivatives- Imine ligands were synthesized in this paper by using many reactions such as cyclization reaction, chalcone reaction in basic medium, condensation reaction to format four new ligands included heterocycles represented by oxazole, thiophene, thiazole derivatives with imine group in same compounds. The four ligands have been identified by several methods such as spectra of (UV-Visible investigation, 1H NMR, FT.IR) and study of chromatographic applications for all ligands.
\end{abstract}

Keywords: React, derivative, form.

\section{Introduction}

Thiazole, Oxazole and thiophene are an important cycles in many bio-molecules Because of their activity in most biosystems and their spectrum in medicinal fields, in pharmaceutical uses, in synthetic chemistry in more than field ${ }^{(1-11)}$ :

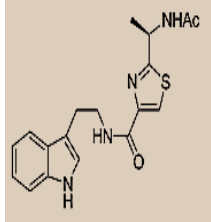

Bacillamide C Thiazole Precursor

Fig.1: Thiazole, Oxazole in Medical field

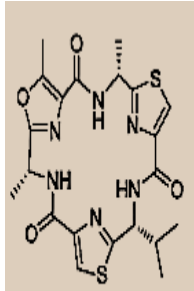

Venturamide A
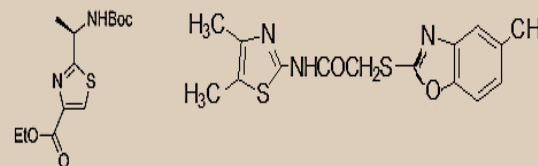

Antimicrobial
Fig. 2: Thiazole, Oxazole inBiomolecules and drugs

Imine compounds are of the most important class of chemical compounds ${ }^{(12-24)}$, which were formatted firstly by Hugo Schiff in year 1864 which prepared by condensation ${ }^{(25-40)}$ reaction between carbonyl compounds such as aldehydes or ketones and primary aromatic amine compounds.

\subsection{Experimental part}

All starting materials in high purity, the characterization carried out with spectrophotometric techniques: Uv-Vis spectra., FT.IR spectra were recorded on a Perkin Elmer-spectrum with(KBr)disc. H.NMR spectra were recorded by using (DMSO$\mathrm{d}_{6}$ ) as a solvent and chromatography technique.

\subsection{Synthesis of Ligand[1]}

Diethyl maliete $(0.1$ mole) was reacted in condensation reaction with $(0.2 \mathrm{~mole})$ of ortho-phenyldiamine with presence of absolute ethanol for ( $3 \mathrm{hrs})$, the resulting compound $(0.01$ mole) refluxed with $(0.02$ mole $)$ ortho-formal benzaldehyde with drops of glacial acetic acid ,the resulting compound was filtered, dried and recrystallized according to literatures ${ }^{(11,19,20)}$ to yield ligand [1]. 


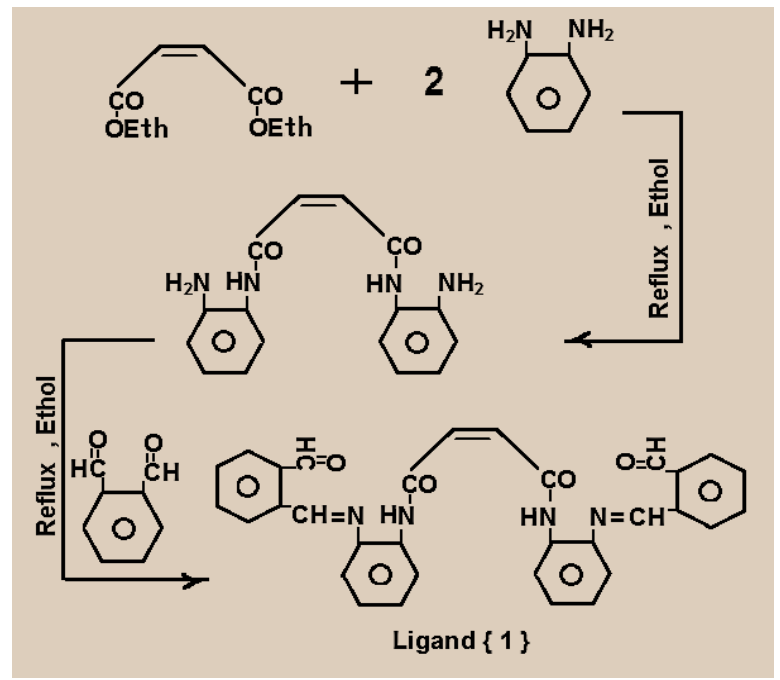

Scheme 1: Preparation of Ligand [1]

\subsection{Synthesis of ligand [2]}

Ligand $\{1\}$ (0.1 mole) was refluxed with ( $0.2 \mathrm{~mole})$ of orthothiolaniline with $(4 \mathrm{~N})$ of hydrochloric acid, the resulting compound was filtered, dried and recrystallized according to literatures $^{(15,19)}$ to obtain ligand [2].

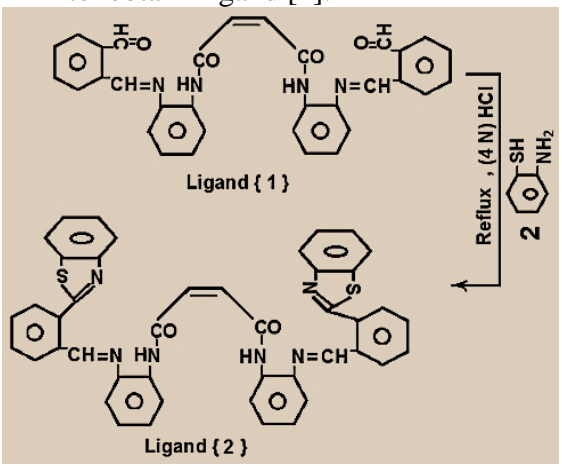

Scheme 2: Preparation ofligand [2]

\subsection{Synthesis of ligand [3]}

Ligand $\{1\}$ (0.1 mole) was refluxed with (0.2mole) of orthothiolphenolwith (4N) of hydrochloric acid, the resulting compound was filtered, dried and recrystallized according to literatures $^{(15,33)}$ to obtain ligand [3].

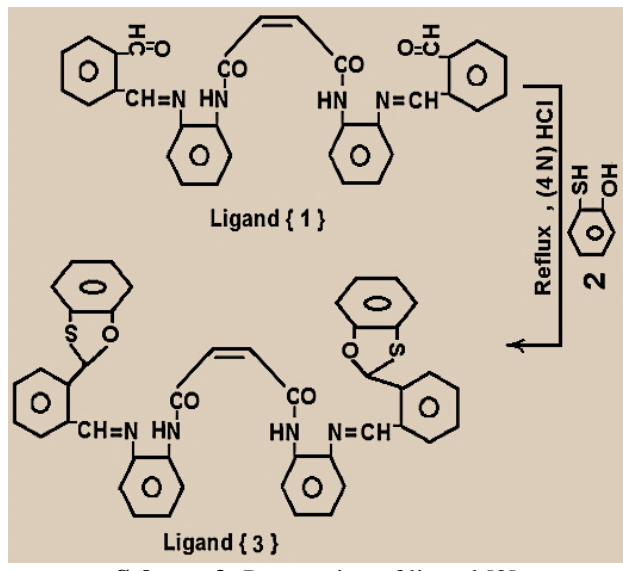

Scheme 3: Preparation of ligand [3]

\subsection{Synthesis of ligand [4]}

The ligand $\{1\}(0.01 \mathrm{~mol})$ was reacted with 2-acetothiophene ( 0.02 mole) with ( $10 \%$ of sodium hydroxide) solution in room temperature, the resulting compound filtered, dried, and recrystallized with ethanol according to literatures ${ }^{(15,19)}$ to give ligand [4]

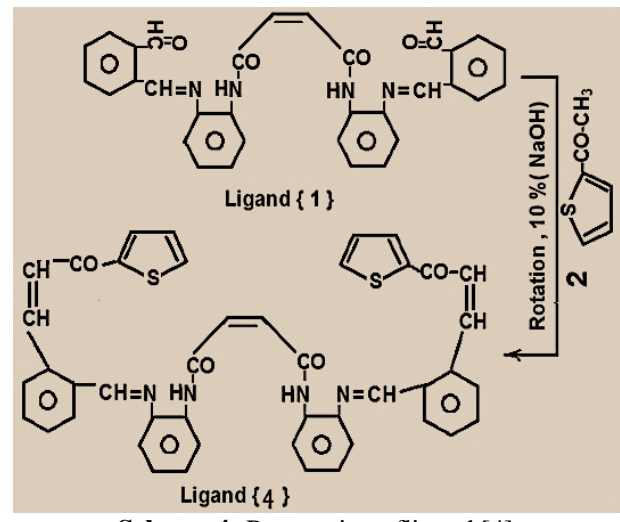

Scheme 4: Preparation ofligand [4]

\section{Results and discussion}

Oxazole and thiazole have a wide spectrum of applications and uses in most chemistry fields ., in this work, we synthesized four new ligands linked with imine group in same compounds., then chemical and spectral identification, study of chromatographic applications:

\subsection{Characterization methods}

UV-Visible Identification: It found by scanning of several solutions of ligands for maximum wave length of four ligands by using Uv-Visible spectrophotometer:

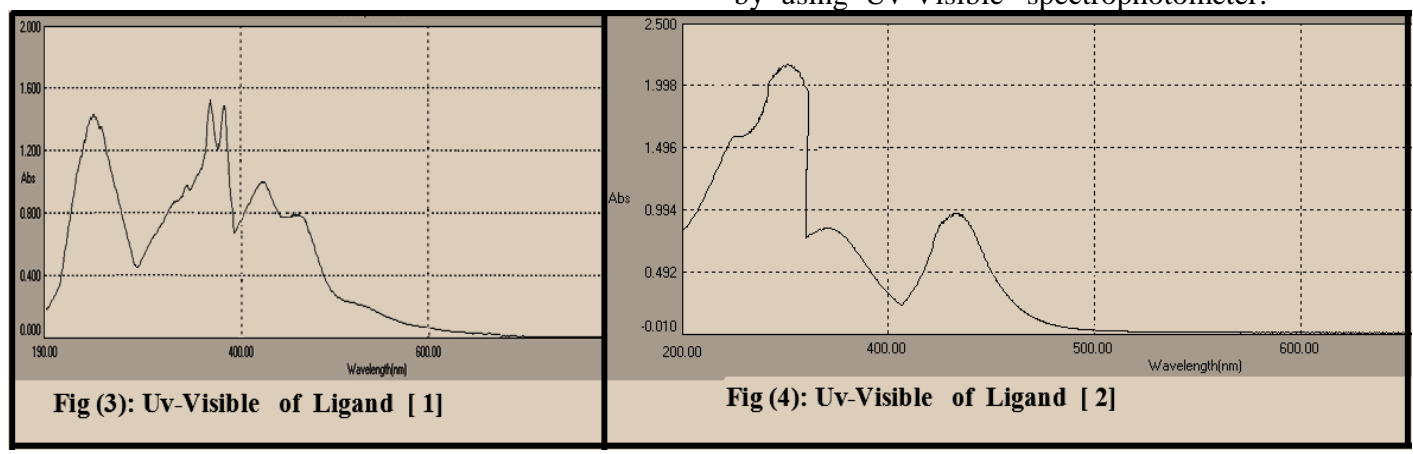




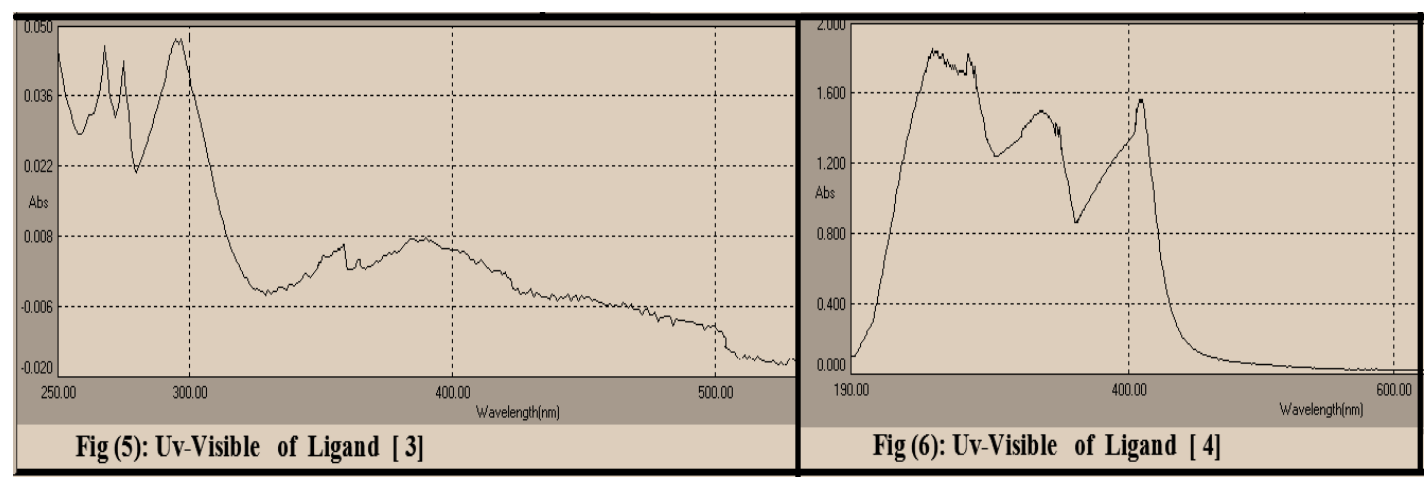

The FT.IR- Identification :It showed absorption bands at ($\mathrm{CH}=\mathrm{N}-$ )Imine group:(1606)., (CO-H-)carbonyl of aldehyde: 1700,(NH-CO-)amine of amide: $3250,(\mathrm{CO}-\mathrm{N}-)$ carbonyl of amide : $1688,(\mathrm{CH}=\mathrm{CH})$ alkene: 3064 in ligand(1), but other bands $(-\mathrm{CH}=\mathrm{N}-)$ Imine group: (1622), (NH-CO-)amine of amide: $3260,(\mathrm{CO}-\mathrm{N}-)$ carbonyl of amide: $1690,(\mathrm{CH}=\mathrm{CH})$ alkene: bands $(-\mathrm{CH}=\mathrm{N}-)$ Imine group: (1618), (NH-CO-)amine of amide: 3254 , (CO-N-) carbonyl of amide : $1686,(\mathrm{CH}=\mathrm{CH})$ alkene: 3074 ,.(C-O ) endocycle of oxazole: 1246in ligand(3) ., but in Ligand (4) showed bands (-CH=N-) Imine group: (1613) ,(NH-CO-) amine of amide: $3241,(\mathrm{CO}-\mathrm{N}-)$ carbonyl of amide : 1678, $(\mathrm{CH}=\mathrm{CH})$ alkene: 3081., $(\mathrm{CO}-\mathrm{CH}=\mathrm{CH}-)$ cabonyl of chalcone : 1694in ligand(4), other functional bands are seen in figures( 7,8$)$.

3067., $(\mathrm{C}=\mathrm{N})$ endocycle of thiazole: 1640 in ligand(2)., other

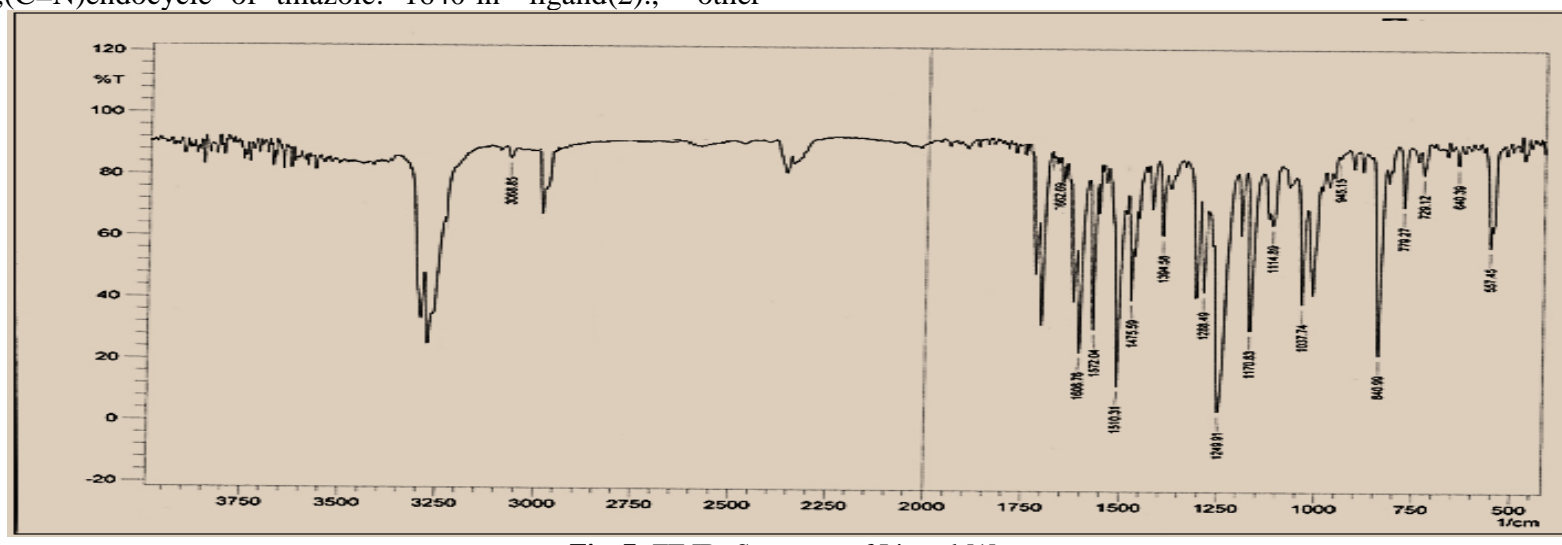

Fig. 7: FT.IR- Spectrum of Ligand [1].

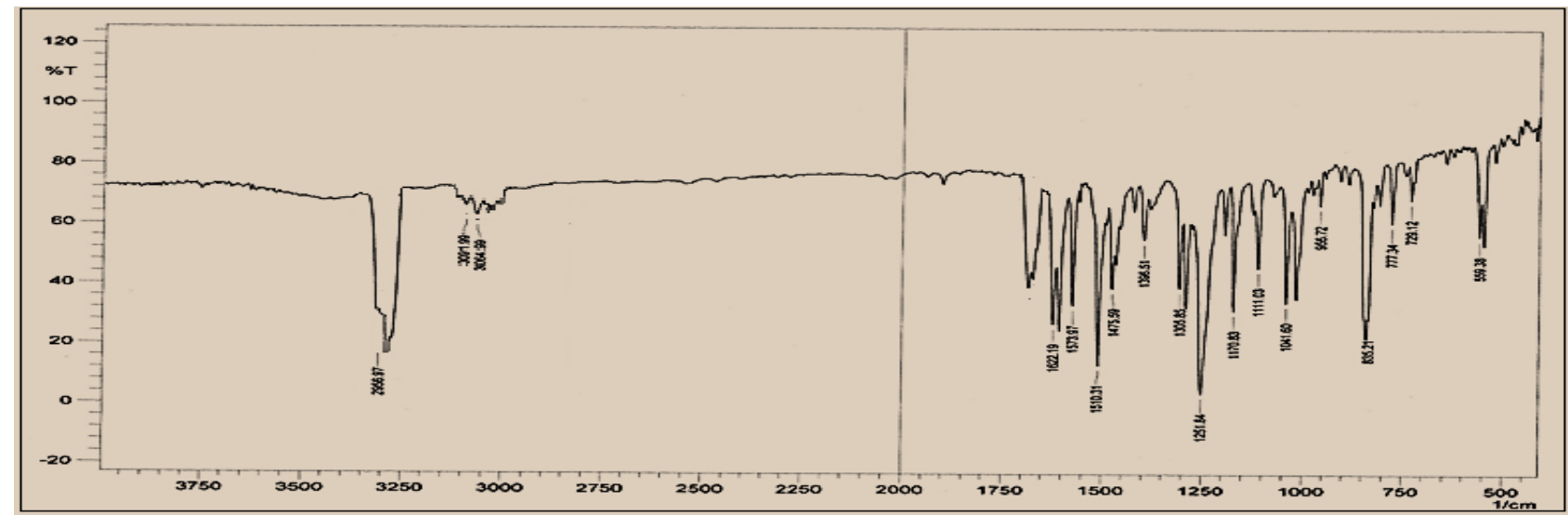

Fig. 8: FT.IR - Spectrum of Ligand [2]

The ${ }^{1}$ H.NMR- Identification: It was foundmany signals at $\mathrm{b}$ DMSO-d6(solvent ): 2.50., proton of aldehyde $(\mathrm{CO}-\mathrm{H}): 11.24$, (NH-CO-)amide : 9.46, Protons of Aromatic ring: (7.25-7.52), $(\mathrm{CH}=\mathrm{N})$ Imine group: 8.37, $(\mathrm{CH}=\mathrm{CH}-)$ protons: $(5.30,5.71)$ in ligand (1), (NH-CO-)amide : 9.32, Protons of Aromatic ring : (7.11-7.69), $(\mathrm{CH}=\mathrm{N})$ Imine group: $8.21,(\mathrm{CH}=\mathrm{CH}-)$ protons : $(5.27$ $, 5.60)$ in ligand (2), also it gave (NH-CO-)amide : 9.84 , Protons of Aromatic ring : (7.16-7.49), $(\mathrm{CH}=\mathrm{N})$ Imine group: 8.56 , $(\mathrm{CH}=\mathrm{CH}-)$ protons : $(5.27,5.60)$ in ligand $(3)$, the spectrum gave (NH-CO-)amide : 9.22, Protons of Aromatic ring : (6.99-7.51), $(\mathrm{CH}=\mathrm{N})$ Imine group: $8.25,(\mathrm{CH}=\mathrm{CH}-\mathrm{CO})$ protons of chalcone : $(5.73,5.93)$ in ligand (4)., and functional signals are shown in figures $(9,10,11)$. 


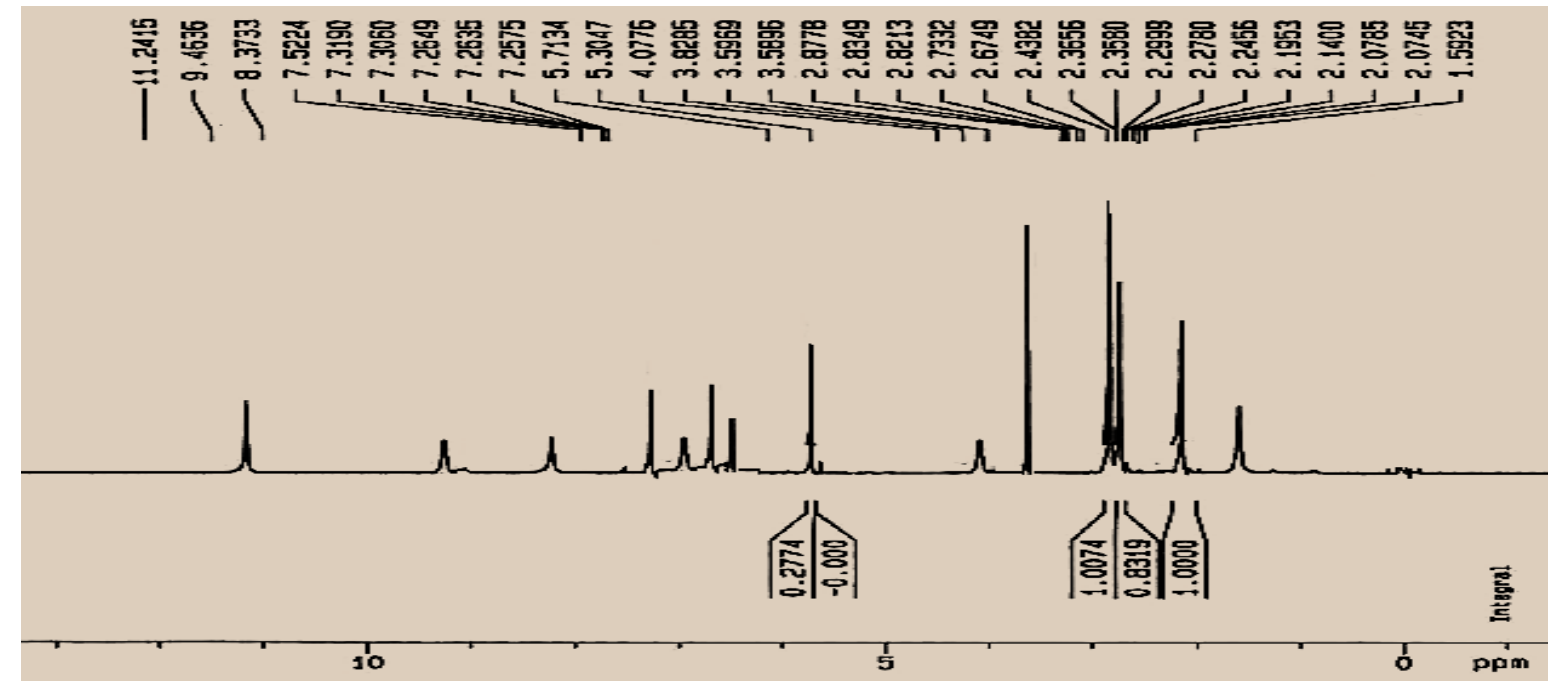

Fig. 9: H.NMR - Spectrum of Ligand [1]
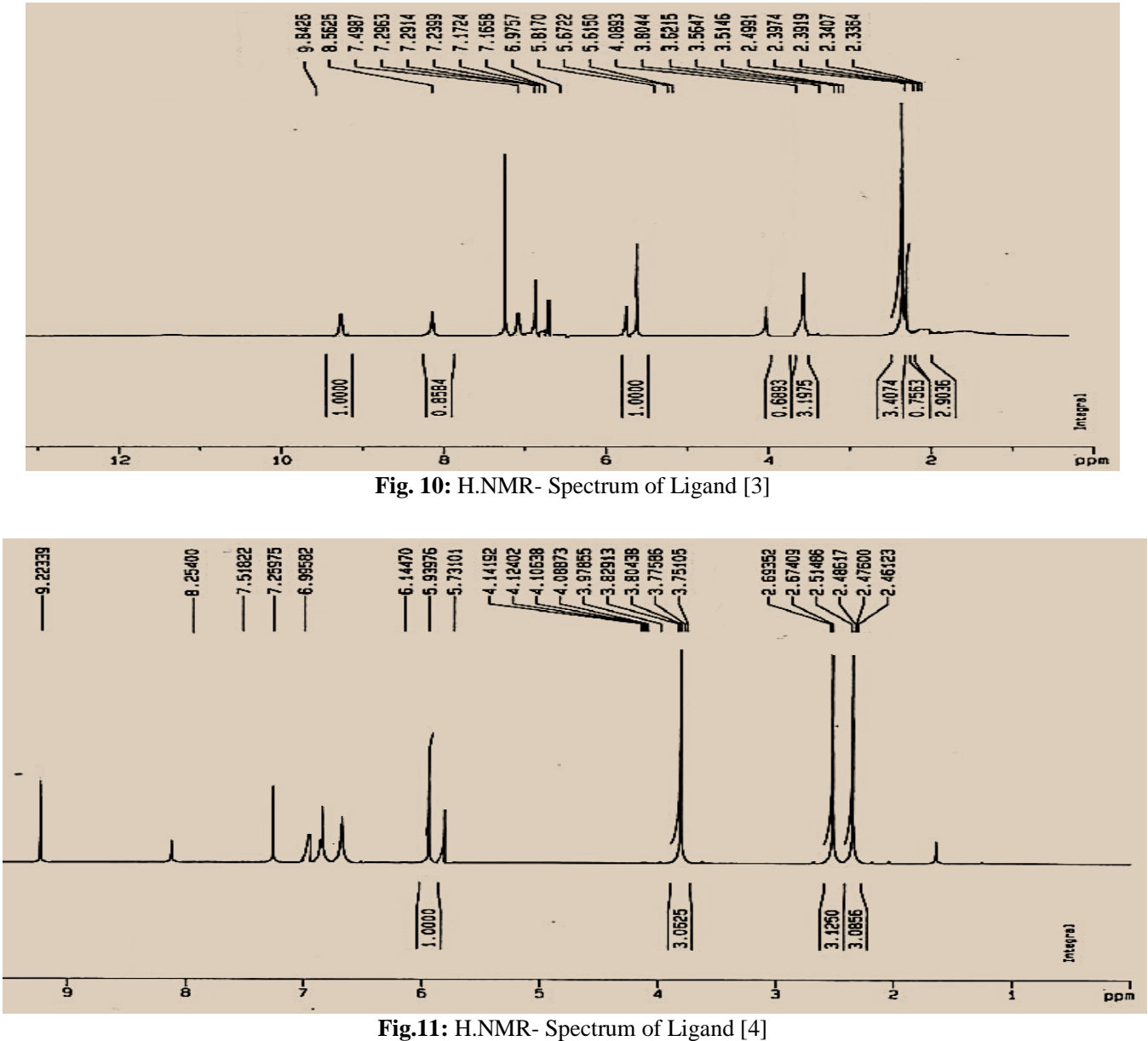

\subsection{Chromatographic study ${ }^{(11)}$ of ligands}

Many diluted concentration (1 ppm) from our ligands were prepared, after that injected with using a syringe (Hamilton ) in capacity (10ml) by using carrier[Nitrogen (gas flow $25 \mathrm{ml} / \mathrm{min}$ )]
The ligands separated according to their polarity and nature of functional groups and their molecular weight .,for this reason compound [4] separated at the last time ${ }^{(11)}$, figures (12-15). 


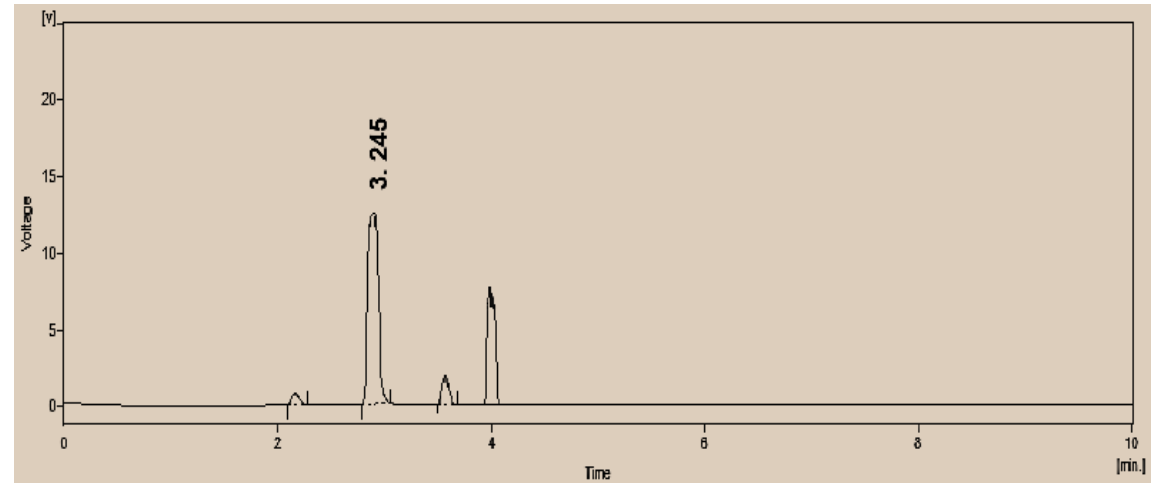

Fig. 12: Chromotogram of Compound [1]

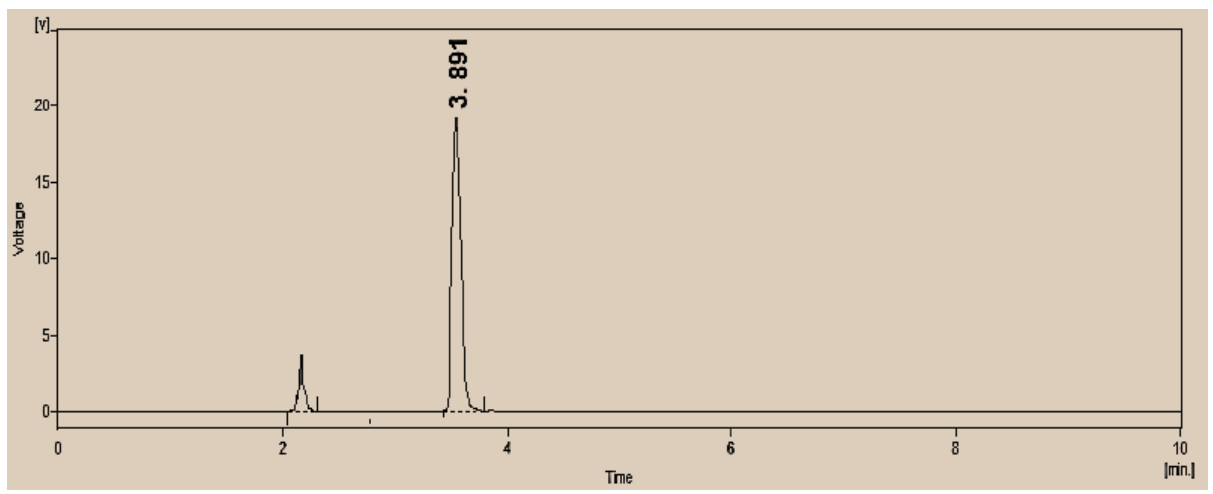

Fig. 13: Chromotogram of Compound [2]

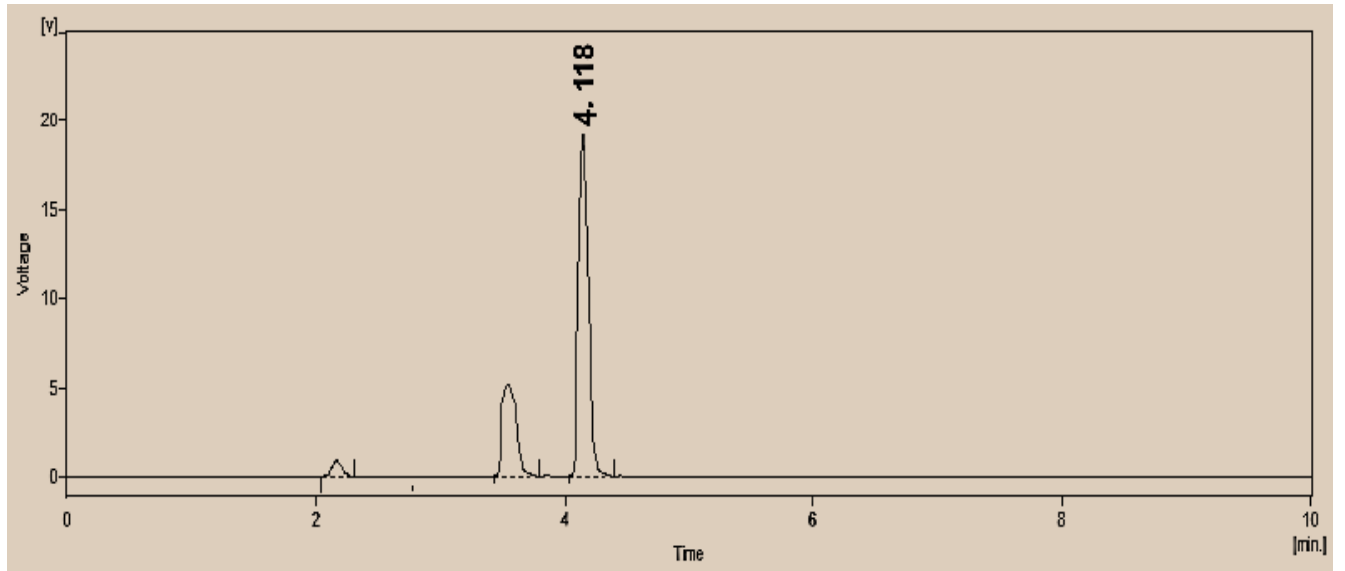

Fig. 14: Chromotogram of Compound [3]

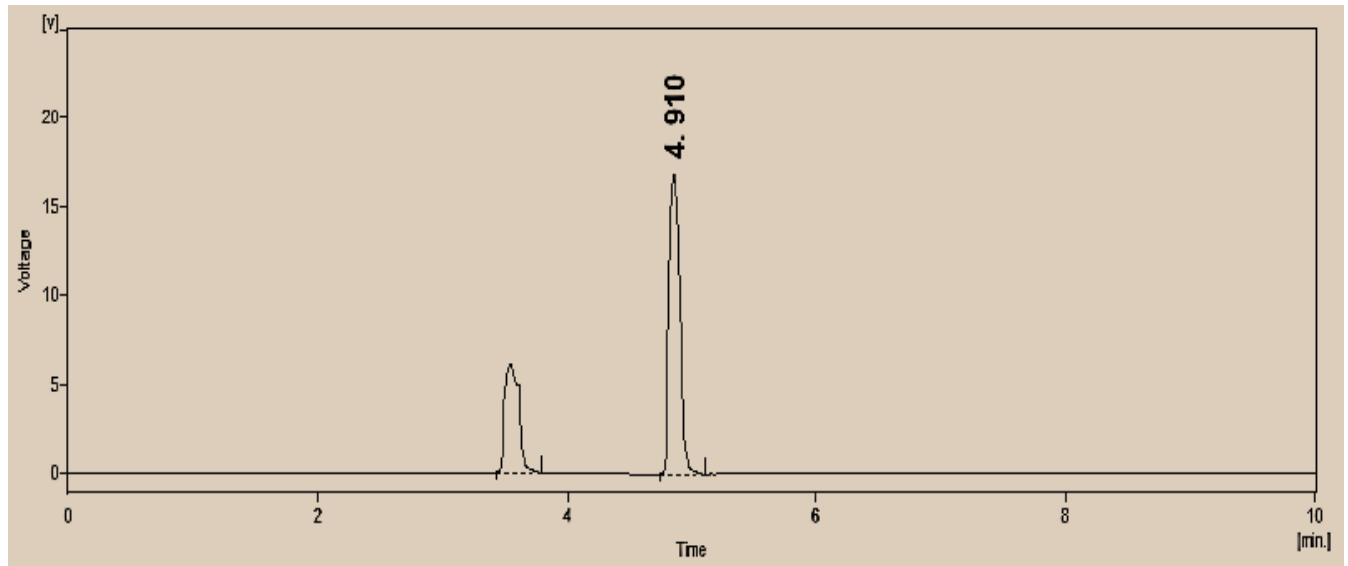

Fig. 15: Chromotogram of Compound [4] 


\section{References}

[1] Young RW \& Wood KH, "The Cyclization of 3Acyldithiocarbazate Esters1", Journal of the American Chemical Society, Vol.77, No.2, (1955), pp.400-403.

[2] Chen H, Li Z \& Han Y, "Synthesis and Fungicidal Activity against Rhizoctoniasolani of 2-Alkyl (Alkylthio)-5-pyrazolyl-1, 3, 4oxadiazoles (Thiadiazoles)", Journal of agricultural and food chemistry, Vol.48, No.11, (2000), pp.5312-5315.

[3] Bauer AW,Kirbay WAW,Sherris JS\& Turk M, "Antibiotic susceptibility testing by a standardized single disc method", American Journal Clinical Pathology, Vol.45, No.4, (1996), pp.493-496.

[4] Filali Baba Y, Elmsellem H, KandriRodi Y, Steli H, AD5 C, Ouzidan Y,OuazzaniChahdi F, Sebbar NK, EssassiEM \&Hammouti B,Der PharmChemica, Vol.8, No.4,(2016), pp.159-169.

[5] Kiran MK, Sagar AJ, Pramod BP, Vikas RDSSP, Der PharmaChemica, Vol.8, No.4,(2016), pp.1-5.

[6] Chao SJ, Hui XP, Li S, Qiu ZZ, Xu PF, Zhang ZY \& Guan ZW, "Synthesis and Antibacterial Activities of Novel Biphenyltetrazole Derivatives Bearing 1, 3, 4-Oxadiazole", Journal of the Chinese Chemical Society, Vol.52, No.3, (2005), pp.539-544.

[7] Srinivas K, Srinivas U, Bhanuprakash K, Harakishore K, Murthy USN \&Rao VJ, "Synthesis and antibacterial activity of various substituted s-triazines", European journal of medicinal chemistry, Vol.41, No.11, (2006), pp.1240-1246.

[8] Tripathi KD, "Antihypertensive drugs", Essentials of Medical Pharmacology, 6th ed. New Delhi: Jaypee Brothers Medical Publishers, (2008), pp.539-43.

[9] AateshÈznur K, "CesurNesrin, Synthesis and antimicrobial activity of some 5-aryl-2-[(N, N-disubstitutedthiocarbamoylthio) acylamino]-1, 3, 4-oxadiazoles", Farmaco, Vol.53, (1998), pp.541544

[10] Montalbetti CA \&Falque V, "Amide bond formation and peptide coupling”, Tetrahedron, Vol.61, No.46, (2005), pp.10827-10852.

[11] Nagham M Aljamali, "Synthesis, Investigation, Chromatography, Thermal-Behavior of (Five, Seven)-Membered Ring With Azo and Anil Compounds. Pak. J. Biotechnol., Vol.15, No.1, (2018), pp.225-237.

[12] Nanjunda S, Swamy S, Basppa PB, Prabhuswamy B \&Doreswamy $\mathrm{BH}$, "Crystal Structure of Novel 2-butyl-4-chloro-1HImidazolyl-5Carboxaldehyde", European Journal. of Medicinal Chemistry, Vol.41, (2006), pp.531-538.

[13] Jin L, Chen J, Song B, Chen Z, Yang S, Li Q \&Xu R, "Synthesis, structure, and bioactivity of $\mathrm{N}^{\prime}$-substituted benzylidene-3, 4, 5trimethoxybenzohydrazide and 3-acetyl-2-substituted phenyl-5- (3, 4, 5-trimethoxyphenyl)-2, 3-dihydro-1, 3, 4-oxadiazole derivatives", Bioorganic \& Medicinal Chemistry Letters, Vol.16, No.19, (2006), pp.5036-5040.

[14] Aboraia AS, Abdel-Rahman HM, Mahfouz NM \& El-Gendy MA, "Novel 5-(2-hydroxyphenyl)-3-substituted-2, 3-dihydro-1, 3, 4oxadiazole-2-thione derivatives: promising anticancer agents", Bioorganic \& medicinal chemistry, Vol.14, No.4, (2006), pp.12361246.

[15] Nagham M Aljamali.,"Preparation, Spectral Investigation, Thermal Analysis, Biochemical Studying of New (Oxadiazole-Five Membered Ring)-Ligands", Journal of Global Pharma Technology, Vol.10, No.1, (2018), pp.20-29.

[16] Uribe-Romo FJ, Hunt JR, Furukawa H, Klock C, O’Keeffe M \&Yaghi OM, "A crystalline imine-linked 3-D porous covalent organic framework", Journal of the American Chemical Society, Vol.131, No.13, (2009), pp.4570-4571.

[17] Hathaway B\&Billing DE, "The electronic properties and stereochemistry of mono-nuclear complexes of the copper (II) ion", Coordination Chemistry Reviews, Vol.5, No.2, (1970), pp.143-207.

[18] Singh RV, Dwivedi R \& Joshi SC, "Synthetic, magnetic, spectral, antimicrobial and antifertility studies of dioxomolybdenum (VI) unsymmetrical imine complexes having a Nก N donor system", Transition Metal Chemistry, Vol.29, No.1, (2004), pp70-74.

[19] Nagham M Aljamali\&Alfatlawi IO, "Synthesis of sulfur heterocyclic compounds and study of expected biological activity", Research Journal of Pharmacy and Technology, Vol.8, No.9, (2015), pp.1225-1242.
[20] Mohammed M, Nagham M Aljamali, Abdalrahman SA \&Shubber WA, "Formation of Oxadiazole Derivatives Ligands From Condensation and Imination Reaction With Reference to Spectral Investigation, Thermal And Microbial Assay", Biochem. Cell. Arch., Vol.18, No.1, (2018), pp.847-853.

[21] Nozaki H, Takaya H, Moriuti S \&Noyori R, "Homogeneous catalysis in the decomposition of diazo compounds by copper chelates: Asymmetric carbenoid reactions", Tetrahedron, Vol.24, No.9, (1968), pp.3655-3669.

[22] Hindson JC, Ulgut B, Friend RH, Greenham NC, Norder B, Kotlewski A \&Dingemans TJ, "All-aromatic liquid crystal triphenylamine-based poly (azomethine) $\mathrm{s}$ as hole transport materials for opto-electronic applications", Journal of Materials Chemistry, Vol.20, No.5, (2010), pp.937-944.

[23] Cremlyn RJW, An introduction to organosulfur chemistry, John Wiley \& Sons Inc, (1996).

[24] GarcíaRuano JL, Cid MB, Martín Castro AM \&Alemán J, "Acyclic S, S-Dialkylsulfimides", Kambe, N. Science of Synthesis, Vol.39, (2008), pp.352-375.

[25] Nagham M Aljamali, Saher M J, Zainab M J\&Alfatlawi IO, "Inhibition Activity of (Azo-Acetyl acetone) on Bacteria of Mouth", Research J. Pharm. and Tech, Vol.10, No.6, (2017), pp.1683-1686.

[26] Drabowicz J, Lewkowski J, Kudelska W \&Girek T, "SDialkylsulfoximides", Kambe, N. Science of Synthesis, Vol.39, (2008), pp.154-173.

[27] Drabowicz J, Lewkowski J, Kudelska W \&Girek, T, "SDialkylsulfonediimines", Kambe, N. Science of Synthesis, Vol.39, (2008), pp.173-180.

[28] Zhang Y\& Hogg N, "S-Nitrosothiols: cellular formation and transport", Free radical biology and medicine, Vol.38, No.7, (2005), pp.831-838.

[29] Nagham M Aljamali, "Synthesis of New Organic Compounds Via Three Components Reaction with Studying of (Identification, Thermal Behavior, Bioactivity on Bacteria of Teeth)", Journal of Global Pharma Technology, Vol.11, No.9, (2018), pp.157-164. $\begin{array}{lllll}\text { [30] Braverman S, Cherkinsky } & \mathrm{M} & \text { \&Levinger } & \mathrm{S} \text {, } \\ \text { "AlkylsulfurTrihalides", } \quad \text { In } & \text { Kambe, } & \text { N. Science } & \text { of }\end{array}$ SynthesisThieme., Vol.39, (2008), pp.187-188.

[31] Drabowicz J, Lewkowski J, Kudelska W \&Girek T, "Dialkylsulfur Tetrahalides", In Kambe, N. Science of Synthesis Thieme., Vol.39, (2008), pp.123-124.

[32] Arora P, Arora V, Lamba HS \&Wadhwa D, "Importance of Heterocyclic Chemistry: A Review", Int J Pharm Res Sci., Vol.3, No.9, (2012), pp.2947-2955.

[33] Nagham M Aljamali\&Rahi D, "New Formazan Compounds (Synthesis, Identification, Physical Properties)", Journal of Chemical and Pharmaceutical Sciences, Vol.10, No.3, (2017), pp.1461-1472.

[34] Sreedaran S, Bharathi KS, Rahiman AK, Rajesh K, Nirmala G, Jagadish L \& Narayanan V, "Synthesis, electrochemical, catalytic and antimicrobial activities of novel unsymmetrical macrocyclicdicompartmental binuclear nickel (II) complexes", Polyhedron, Vol.27, No.7, (2008), pp.1867-1874.

[35] Eman HS \&Nagham M Aljamali, "New Azo-Thiadiazole Ligands (Preparation, Spectral, Thermal, Biochemical, Physical properties)Studying", Journal of Global Pharma Technology, Vol.11, No.9, (2017), pp.165-173.

[36] Nakamoto K, "Infrared and R aman Spectra of Inorganic and Coordination Compounds", Handbook of Vibrational Spectroscopy, (2006).

[37] Schneider I, Keuleyan E, Rasshofer R, Markovska R, Queenan AM \&Bauernfeind A, "VIM-15 and VIM-16, two new VIM-2-like metallo- $\beta$-lactamases in Pseudomonas aeruginosa isolates from Bulgaria and Germany", Antimicrobial agents and chemotherapy, Vol.52, No.8, (2008), pp.2977-2979.

[38] Bogaerts P, Bauraing C, Deplano A \&Glupczynski Y, "Emergence and dissemination of BEL-1-producing Pseudomonas aeruginosa isolates in Belgium", Antimicrobial agents and chemotherapy, Vol.51, No.4, (2007), pp.1584-1585. 